OPEN ACCESS

Edited by:

Xinjiang $L u$,

Ningbo University, China

Reviewed by:

Katherine Buckley,

Auburn University, United States

Hai-peng Liu,

Xiamen University, China

*Correspondence:

Leon Grayfer

leon_grayfer@gwu.edu

†Present address:

Phillip Reeves,

Department of Biology, University of Virginia, Charlottesville, VA,

United States

Specialty section:

This article was submitted to

Comparative Immunology,

a section of the journal

Frontiers in Immunology

Received: 23 August 2019 Accepted: 09 December 2019

Published: 22 January 2020

Citation:

Yaparla A, Reeves P and Grayfer L (2020) Myelopoiesis of the Amphibian

Xenopus laevis Is Segregated to the Bone Marrow, Away From Their Hematopoietic Peripheral Liver.

Front. Immunol. 10:3015. doi: 10.3389/fimmu.2019.03015

\section{Myelopoiesis of the Amphibian Xenopus laevis Is Segregated to the Bone Marrow, Away From Their Hematopoietic Peripheral Liver}

\author{
Amulya Yaparla ${ }^{1}$, Phillip Reeves ${ }^{2 \dagger}$ and Leon Grayfer ${ }^{1 *}$ \\ ${ }^{1}$ Department of Biological Sciences, George Washington University, Washington, DC, United States, ${ }^{2}$ School Without Walls \\ High School, Washington, DC, United States
}

Across vertebrates, hematopoiesis takes place within designated tissues, wherein committed myeloid progenitors further differentiate toward cells with megakaryocyte/erythroid potential (MEP) or those with granulocyte/macrophage potential (GMP). While the liver periphery (LP) of the Xenopus laevis amphibian functions as a principal site of hematopoiesis and contains MEPs, cells with GMP potential are instead segregated to the bone marrow (BM) of this animal. Presently, using gene expression and western blot analyses of blood cell lineage-specific transcription factors, we confirmed that while the $X$. laevis LP hosts hematopoietic stem cells and MEPs, their BM contains GMPs. In support of our hypothesis that cells bearing GMP potential originate from the frog LP and migrate through blood circulation to the BM in response to chemical cues; we demonstrated that medium conditioned by the $X$. laevis BM chemoattracts LP and peripheral blood cells. Compared to LP and by examining a comprehensive panel of chemokine genes, we showed that the $X$. laevis BM possessed greater expression of a single chemokine, CXCL12, the recombinant form of which was chemotactic to LP and peripheral blood cells and appeared to be a major chemotactic component within BM-conditioned medium. In confirmation of the hepatic origin of the cells that give rise to these frogs' GMPs, we also demonstrated that the $X$. laevis BM supported the growth of their LP-derived cells.

Keywords: hematopoiesis, myelopoiesis, peripheral liver, bone marrow, CXCL12

\section{INTRODUCTION}

Across all vertebrates, pluripotent pre-committed and lineage-committed blood cell precursors reside within designated hematopoietic sites (1). During blood cell lineage commitment, the pluripotent stem cells give rise to common lymphoid (2) and common myeloid (3) progenitors (CLPs and CMPs, respectively). The CLPs further differentiate into B and T cell precursors, while the CMPs give rise to precursors of the megakaryocyte/erythroid (MEPs) or granulocyte/macrophage potential (GMPs) (3). Site(s) of adult animal hematopoiesis vary across vertebrata, from bone marrow in reptiles $(4)$, birds $(5,6)$, and most mammalian species (7) to the head kidney in teleost fish $(8,9)$. In turn, the differentiation of GMPs toward the macrophage lineage depends on the activation of the colony stimulating factor-1 receptor (CSF-1R) (10) by its cognate ligand, colony stimulating factor-1 (CSF-1), which acts as a monopoietic growth 
factor (11, 12). Similarly, the differentiation of MEPs toward the erythroid lineage depends on erythropoietin (EPO) $(13,14)$. Notably, while the peripheral (subcapsular) liver of the anuran amphibian Xenopus laevis is considered to be the principal site of hematopoiesis (14-16), we demonstrated that the cells responsive to CSF-1 reside in the $X$. laevis bone marrow and are absent from their peripheral liver $(17,18)$. Conversely, we (17) and others (14) showed that the $X$. laevis peripheral liver, but not their bone marrow, contains cells that respond to EPO to form erythroidlineage cells. To date, the ontogeny of $X$. laevis bone marrow GMPs remains poorly understood.

The step-wise lineage commitment of pluripotent cells depends on external stimuli, including specific growth factors akin to CSF-1 and EPO, and progenitor cell-stromal cell interactions $(19,20)$. Concurrently, these commitment steps are marked by changes in gene expression of cell lineagespecific transcription factors, which are thus often used as markers to identifying the respective, lineage-committed cell populations (19-21). For example and pertinently to this work, as CMPs commit to MEPs or GMPs, they exhibit increased expression of fli1, gata1, and $n f e 2$ or pul, egrl, egr2, and gfil, respectively (19-21).

The retention of progenitors and certain committed blood cells within hematopoietic tissues, as well as the mobilization and homing of specific cell populations to disparate tissues within organisms, is mediated by designated chemokines (22). In general, chemokines are classified into four families based on the presence and positioning of conserved cysteine residues: $\mathrm{C}$, CC, CXC, and CX3C (23). Chemokines typically act through cellsurface G-protein-coupled seven-transmembrane receptors and have been most thoroughly described in the context of leukocyte recruitment during immune responses (23). Conversely, the roles of chemokines in hematopoiesis first became evident from the analyses of the interaction between CXCL12 (also known as stem cell derived factor-1) and its receptor CXCR4 in mice, wherein the inactivation of the $\operatorname{cxcl} 12$ and $\mathrm{cxcr} 4$ genes resulted in defective hematopoiesis, cardiogenesis, and vascular development (24-26). The biological roles of CXCL12 have also been examined in other vertebrates such as fish and avian species, wherein studies have demonstrated the roles of CXCL12 in muscle formation, vascular development, and homing of hematopoietic stem cells (26-28). While the roles of the amphibian CXCL12 have not been extensively studied, the X. laevis CXCL12 has been shown to activate the frog CXCR4 (29).

Here we examine the $X$. laevis peripheral liver as a potential source of precursor cells to GMPs and assess the putative role of CXCL12 in homing of these cells to the myelopoietic bone marrow of this animal.

\section{MATERIALS AND METHODS}

\section{Animals, Culture Media and Conditions}

Outbred, $\sim 1$ - to 2-year-old adult $X$. laevis were purchased from Xenopus1 (Dexter, MI), housed, and handled under strict laboratory regulations of Animal Research Facility at the George Washington University (GWU) and as per the
GWU Institutional Animal Care and Use Committee regulations (approval number 15-024).

All cell cultures were established in amphibian serum-free medium supplemented with $10 \%$ fetal bovine serum, $0.25 \% X$. laevis serum, $10 \mu \mathrm{g} / \mathrm{ml}$ gentamycin (Thermo Fisher Scientific), $100 \mathrm{U} / \mathrm{ml}$ penicillin, and $100 \mu \mathrm{g} / \mathrm{ml}$ streptomycin (Gibco). Amphibian phosphate-buffered saline (APBS) that was used while isolating the cells has been previously described (18).

\section{Production of Frog Recombinant Cytokines and Chemokines}

$X$. laevis recombinant ( $\mathrm{r}$ )CSF-1, rEPO, and $\mathrm{rCXCL} 12$ were produced using an Sf9 insect cell expression system by a previously described method (18). Briefly, PCR amplicons corresponding to the open reading frames of the respective signal peptide-cleaved proteins were ligated into the pMIB/V5 His A vector. Sf9 insect cells were transfected with the expression constructs (Cellfectin II, Invitrogen), and positive transfectants were selected using $10 \mu \mathrm{g} / \mathrm{ml}$ of blasticidin, their supernatants were screened for recombinant production by western blot against the V5 epitope on the proteins. The cultures expressing rCSF-1, rEPO, or rCXCL12 were scaled up and grown as 500$\mathrm{ml}$ cultures for 5 days, and their supernatants were collected by centrifugation, concentrated against polyethylene glycol flakes $(8 \mathrm{kDa})$ at $4^{\circ} \mathrm{C}$, and dialyzed for 2 days against $150 \mathrm{mM}$ sodium phosphate at $4^{\circ} \mathrm{C}$. The recombinant proteins were isolated from these concentrated supernatants via Ni-NTA agarose columns (Qiagen), washed with $2 \times 10$ volumes of high-stringency wash buffer $(0.5 \%$ tween $20,20 \mathrm{mM}$ sodium phosphate, $500 \mathrm{mM}$ sodium chloride, and $100 \mathrm{mM}$ imidazole), and $5 \times 10$ volumes of low-stringency wash buffer (as above, but with $40 \mathrm{mM}$ imidazole). The recombinants were then eluted in 1-ml fractions with $250 \mathrm{mM}$ imidazole. Western blot analysis was performed against the V5 epitopes on rCSF-1, rEPO, and rCXCL12 to confirm the presence of the recombinants. For each protein, the fractions expressing the recombinant were combined and further concentrated against polyethylene glycol flakes $(8 \mathrm{KDa})$ and dialyzed overnight against APBS at $4^{\circ} \mathrm{C}$. The protein concentrations were determined by Bradford protein assays (BioRad), and a protease inhibitor cocktail (Halt protease inhibitor cocktail; Thermo Scientific) was added to the purified proteins, which were then aliquoted and stored at $-20^{\circ} \mathrm{C}$ until use. The composition of the recombinant proteins was tested by western blot against the V5 epitope on the protein (Supplementary Figure 1).

The recombinant control (r-ctrl) was produced by transfecting Sf9 cells with an empty pMIB/V5 His A insect expression vector (Invitrogen), collecting the resulting supernatants and processing these using the same methodology as described for $\mathrm{rCSF}-1 / \mathrm{rEPO} / \mathrm{rCXCL} 12$.

\section{Bone Marrow, Peripheral Liver, and Peripheral Blood Leukocyte Isolation and Culture}

The liver periphery (LP) cells and bone marrow (BM) cells were isolated by a previously described method (30). Briefly, $X$. 
laevis femurs and liver tissues were aseptically excised from five individual frogs $(N=5)$ that had been euthanized by tricaine mesylate overdose and cervical dislocation. Femurs were flushed with $10 \mathrm{ml}$ of ice-cold APBS each, and the flushed cells were washed and re-suspended in culture medium.

The peripheral regions of the frog livers were aseptically peeled off using sterile tweezers and passed through $70-\mu \mathrm{m}$ nylon mesh cell strainers (Fisher). The isolated cells were layered over $51 \%$ percoll (Sigma) $(49 \%$ APBS) and centrifuged at $600 \times g$ at $4^{\circ} \mathrm{C}$ for $20 \mathrm{~min}$ to separate out leukocytes from the red blood cells. The leukocytes containing interfaces were collected and washed with ice-cold APBS prior to culture.

Peripheral blood leukocyte (PBL) isolation was performed as follows. Blood was collected from euthanized animals $(N=5)$ by cardiac puncture into medium (containing $1 \mathrm{mg} / \mathrm{ml}$ heparin) and processed over $51 \%$ percoll, as described above for LP cells, to isolate PBLs.

All cells were enumerated using trypan blue (Invitrogen) live/dead exclusion method.

Toward the analyses of bone marrow chemokine gene expression, the frog femurs were flushed with APBS to remove non-stromal cells and were then repeatedly flushed with Trizol reagent (Invitrogen) to remove stromal/supporting cells. The RNA isolation and cDNA synthesis were carried out as described below.

To assess the effects of monopoietic and erythropoietic stimuli on LP and BM cells, five adult $X$. laevis $(N=5)$ were injected intraperitoneally (ip) with $5 \mu \mathrm{g}$ of rCSF- 1 or rEPO and euthanized 3 days later, and their LP and BM cells were isolated as described above.

\section{Isolation of RNA and Quantitative Gene Expression Analyses}

For all experiments, total RNA from $X$. laevis cells or tissues was isolated using Trizol reagent (Invitrogen) in accordance to the manufacturer's directions. The isolated RNAs (500 ng total) were reverse-transcribed into cDNAs using cDNA qscript supermix (Quanta), according to the manufacturer's instructions.

All quantitative gene expression analyses were performed using the CFX96 Real-Time System and iTaq Universal SYBR Green Supermix (Quanta). The BioRad CFX Manager software was employed for all expression analysis. All gene expression analyses were performed using the delta $\wedge$ delta CT method, with expression examined relative to the gapdh endogenous control. For all experiments, the relative expression was normalized against the lowest observed expression within respective data set. All primers were validated prior to use, and the sequences of all employed primers are listed in Supplementary Table 1.

\section{Western Blot Analyses of Cellular Transcription Factor Protein Levels}

To examine transcription factor expression at the protein level, $X$. laevis LP and BM cells were isolated from three individual frogs $(N=3)$ and lysed in ice-cold radio-immunoprecipitation assay buffer (Thermo Fisher Scientific) in the presence of halt protease and phosphatase inhibitor cocktail (Thermo Fisher Scientific). Protein concentrations of the cell lysates were determined using Bradford protein assays (BioRad), and $30 \mu \mathrm{g}$ of total protein per sample was resolved by SDS-PAGE and examined by western blot using mouse monoclonal antibodies against Tal1, Egr1, Gfi1, and actin (Santa Cruz) and a secondary goat anti-mouse HRPconjugated antibody (Thermo Fisher Scientific). Densitometry was performed using ImageJ software. Prior to western blot analyses, protein sequence alignments of mammalian and $X$. laevis Tal1, Egr1, Gfil, and actin proteins were performed to ensure that the respective epitopes targeted by each of the above antibodies were conserved in the respective $X$. laevis proteins.

\section{Chemotaxis Assays}

Chemotaxis assays were performed using blind well chemotaxis (Boyden) chambers (Neuro Probe), with 100-fold serial dilutions of rCXCL12, concentrations at $10-10^{-7} \mathrm{ng} / \mathrm{ml}$ (in culture medium), loaded into the bottom well of these chambers. The wells were overlaid with $13-\mathrm{mm}$ chemotaxis filters $(5 \mu \mathrm{m}$ pore size; Neuro Probe), with addition of $10^{4}$ LP cells or PBLs in $200-\mu \mathrm{l}$ volumes of culture medium to the upper chambers. Chemotaxis assays were incubated at $27^{\circ} \mathrm{C}$ with $5 \% \mathrm{CO}_{2}$ for $3 \mathrm{~h}$. Subsequently, the cells/medium was removed from the top chambers, and the upper sides of the filters were wiped with cotton swabs. The filters were then stained with Giemsa stain, and the numbers of migrating cells were determined by counting 10 random fields of view per lower side of each filter $(\times 40$ objective). For the chemokinesis experiments, both the lower and the upper wells of the chemotaxis chambers were loaded with the most potent chemoattractive concentrations of rCXCL12 $\left(10^{-3}\right.$ $\mathrm{ng} / \mathrm{ml}$ ), and the assays were performed as above.

For chemotaxis assays using supernatants derived from BM stroma, X. laevis femurs were isolated and gently flushed with $10 \mathrm{ml}$ of APBS to remove any non-stromal cells, thus leaving the stroma intact. The femurs were then incubated overnight $(16 \mathrm{~h})$ in $1 \mathrm{ml}$ of culture medium each, and the following day the femurconditioned medium were centrifuged to remove any cells and debris and concentrated tenfold against polyethylene glycol flakes $(8 \mathrm{KDa})$ at $4^{\circ} \mathrm{C}$. These $\mathrm{BM}$-conditioned media (BM-med) were serially diluted to $10^{-1}$ and $10^{-2}$ and used for chemotaxis assays as described above. Chemokinesis experiments were performed by adding tenfold concentrated BM-med to both upper and lower chemotaxis chambers.

Combined chemotaxis assays of rCXCL12 and BMconditioned medium were performed by either loading rCXCL12 $\left(10^{-3} \mathrm{ng} / \mathrm{ml}\right)$ into lower chemotaxis chambers and BM-med (tenfold concentrated) into upper chambers or viceversa, with the target PBLs or LP cells $\left(10^{4}\right)$ added to upper chambers. The enumerated chemotaxis was compared to cell migration toward the rCXCL12 $\left(10^{-3} \mathrm{ng} / \mathrm{ml}\right)$ or BM-med alone (in lower chambers).

Cells derived from five individual animals $(N=5)$ were used for each and all chemotaxis assays and all assays performed as described above.

\section{In vitro Culture of Peripheral Liver Cells Within Frog Bone Marrow}

Frog femurs and LP cells were isolated as described above. The femurs were cut at the condyles on one side of each bone, thereby creating openings into individual femurs. For each animal, one femur bone was then gently flushed with 
APBS, while the other was flushed with $10 \mathrm{ml}$ of methanol to fix the BM stromal/supporting cells. The isolated LP cells $\left(10^{5}\right)$ from respective animals were introduced into each of the two femurs from the corresponding animal by gently placing the opening side up into $10 \mathrm{ml}$ of semi-solid culture medium $(10 \%$ methyl cellulose) and incubating for 3 days at $27^{\circ} \mathrm{C}$ and $5 \%$ $\mathrm{CO}_{2}$. Subsequent to this incubation, femurs were cut at the opposite condyles, and the cells were collected by flushing each bone with APBS and enumerated using trypan blue live/dead exclusion method. This experiment was repeated three times, each time using cells from six individual animals $(N=6)$ per experiment.

\section{Statistical Analysis}

For all gene expression and densitometry data, statistical analysis was conducted using paired Student's T-test. Chemotaxes data were examined using ANOVA and post-hoc Tukey tests via Graphpad Prism 7.0 software. Probability level of $P<0.05$ was considered significant.
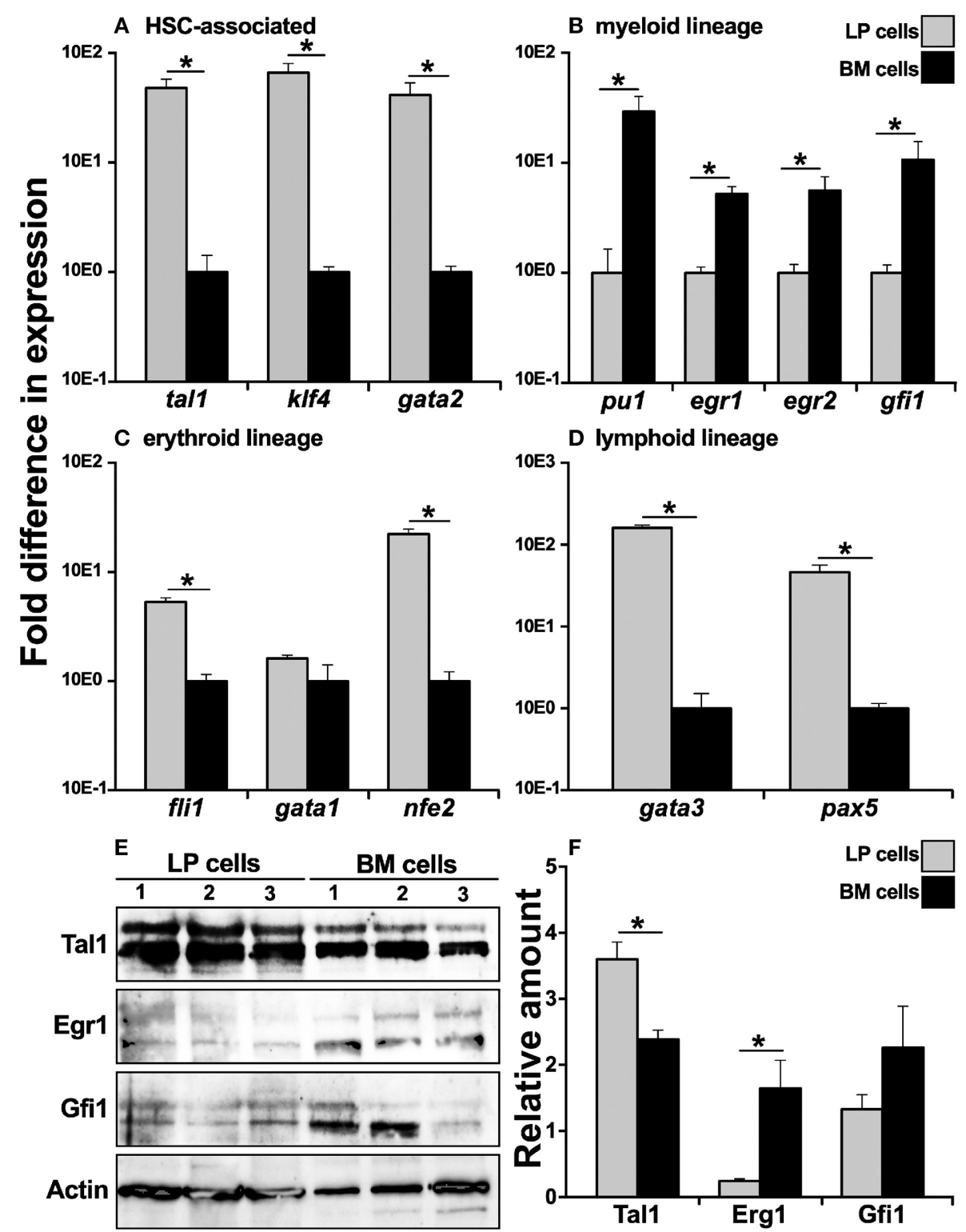

FIGURE 1 | Analysis of lineage-specific transcription factor gene expression in $X$. laevis liver periphery and bone marrow cells. $X$. laevis liver periphery and bone marrow cells were isolated and examined by qPCR for their expression of (A) HSC-associated, (B) myeloid lineage, (C) erythroid-lineage, and (D) lymphoid-lineage transcription factor genes. All gene expressions were quantified relative to the gapdh endogenous control and normalized against the lowest observed expression. 30 $\mu \mathrm{g}$ of total cell lysate proteins from LP and BM cells was used for western blot analysis to determine the protein levels of (E) Tal1, Egr1, and Gfi1 with beta actin as a loading control. The protein levels were quantified by $\mathbf{( F )}$ densitometry analyses using ImageJ software. Results are means \pm SEM $(\mathbf{A}-\mathbf{D}$ : $N=5$; $\mathbf{E}, \mathbf{F}$ : $N=3)$ and asterisk overhead of horizontal lines denotes statistical significance, $P<0.05$ 


\section{RESULTS}

\section{$X$. laevis Peripheral Liver and Bone Marrow Cells Possess Distinct Expression Profiles of Lineage-Specific Transcription Factors}

Since the $X$. laevis peripheral liver is host to most hematopoiesis in this animal (14-16), we examined whether this tissue is the source of cells that commit toward the bone marrow resident granulocyte macrophage precursors (GMPs). To this end, we compared cells from the $X$. laevis $\mathrm{LP}$ and $\mathrm{BM}$ for their respective gene expression of key transcription factors (TFs) associated with distinct blood cell lineage commitment. In comparison to BM cells, the LP-derived cells exhibited greater mRNA levels for TFs associated with hematopoietic stem cells (HSCs), including tal1 (31), klf4 (32), and gata2 (33), thus corroborating that the peripheral liver is the principal hematopoietic site in $X$. laevis (Figure 1A). Interestingly, myeloid lineage-specific TFs, including pu1 (34), egr1 (35), egr2 (36), and gfil (37), were expressed at significantly greater levels by the BM cells compared to the LP cells (Figure 1B), supporting our previous finding that GMPs reside in the $X$. laevis bone marrow and are absent from their peripheral liver $(17,18)$. Furthermore, in comparison to BM cells, the LP cells displayed significantly greater gene expression for erythroid lineage TFs, including fli1(38) and nfe2 (39), while gata1 (40) was expressed at comparable levels in the both cell types (Figure 1C). The lymphoid lineage TFs gata3 (41) and pax5 (42) also displayed significantly greater mRNA levels in the LP cells compared to BM cells (Figure 1D). These findings supported our previous observations that the $X$. laevis peripheral liver hosts most blood cell development, excluding the bone marrow-mediated myelopoiesis (17).

To confirm the respective hematopoietic and myelopoietic nature of the X. laevis LP and BM cells, we assessed the two cell types for their relative protein levels of myeloid (Gfil, Egr1) and HSC-associated (Tal1) transcription factors by western blot (Figures 1E,F). As expected, while LP cells possessed significantly greater protein levels of Tal1 (non-phosphorylated, lower bands; phosphorylated, upper bands), the X. laevis BM cells exhibited relatively more robust Gfil and Egrl (non-phosphorylated, lower bands; phosphorylated, upper bands) protein levels (significantly so for Erg1) (Figures 1E,F).

\section{$X$. laevis Bone Marrow and Liver Periphery Cells Respond to Monopoietic and Erythropoietic Stimuli, Respectively}

Because we observed significantly greater myeloid TF expression by the BM cells, while the erythroid lineage TFs were more robustly expressed by the LP cells (Figures 1B,C, respectively), we next analyzed the expression of these respective lineagespecific markers in LP and BM cells isolated from animals that had been stimulated with recombinant forms of the principal mediators of monopoiesis and erythropoiesis, colony stimulating fator-1 (rCSF-1) or erythropoietin (rEPO), respectively. To this end, frogs were injected intraperitoneally (ip) with rCSF-1 or rEPO, and 3 days later, their LP and BM cells were examined for changes in TF gene expression. Neither LP cells nor BM

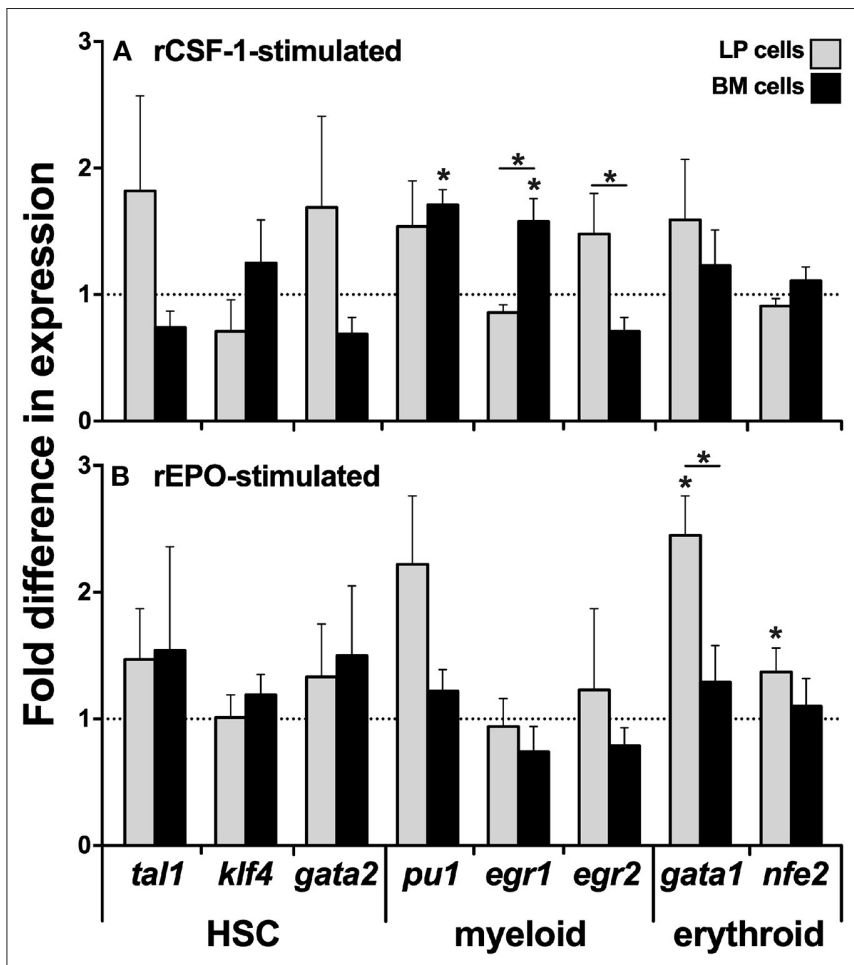

FIGURE 2 | Analysis of lineage-specific transcription factor gene expression in liver periphery and bone marrow cells from rCSF-1- and rEPO-stimulated $X$. laevis. Adult $X$. laevis frogs were injected intraperitoneally with $5 \mu \mathrm{g}$ of rCSF-1, rEPO, or equal volumes of $r$-ctrl, and 3 days later their liver periphery and bone marrow cells were assessed for lineage-specific transcription factor gene expression in (A) rCSF-1-stimulated and (B) rEPO-stimulated cells. The examined genes included hematopoietic-associated TFs: tal1, klf4, gata2, nfe2; myeloid-lineage TFs: pu1, egr1, egr2; and erythroid lineage TFs: gata1, $n f e 2$. All gene expressions was quantified relative to the gapdh endogenous control and the gene expression is presented relative to the respective gene expression in $r$-ctrl-treated animals; denoted by dashed lines. Results are means \pm SEM $(N=5)$ and asterisk overhead of horizontal lines denote statistical significance between the two cell types and $\left({ }^{*}\right)$ denotes statistical differences between the $r$-ctrl and respective r-growth factor stimulation, within respective cell types, $P<0.05$.

cells from animals stimulated with either growth factor exhibited significant differences in their gene expression of the HSCspecific tal1 and klf4 TFs (Figures 2A,B). Interestingly, LP cells from $\mathrm{rEPO}$-stimulated animals possessed significantly greater transcript levels for the erythroid TFs gatal and $n f e 2$ (Figure 2B). Conversely, BM cells, but not LP cells from rCSF-1-treated animals, exhibited a significantly elevated expression of the myeloid TFs pul and egr1 (Figure 2A). We did not observe changes in the expression of other examined myeloid lineage or HSC-specific TFs in the LP and BM cells from rCSF-1- and rEPO-stimulated frogs (Figures 2A,B).

\section{X. laevis Bone Marrow Produces Factors That Are Chemoattractive to Peripheral Liver Cells and Blood Leukocytes}

We hypothesized that the $X$. laevis myeloid precursors originate in the LP and are traffick through blood circulation to the BM 


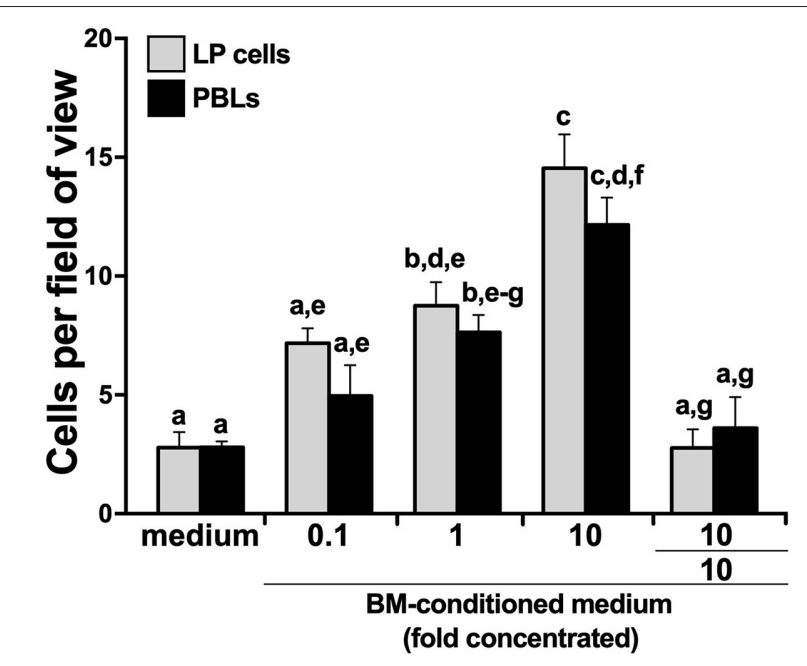

FIGURE $3 \mid X$. laevis bone marrow-conditioned medium chemoattracts peripheral liver and blood leukocytes. Tenfold concentrated bone marrow-conditioned medium was serially diluted and examined for its ability to chemo-attract liver periphery (LP) cells and peripheral blood leukocytes (PBLs). Chemokinesis of LP cells and PBLs was measured by adding the tenfold concentrated BM-medium to both the upper and the lower chemotaxis chambers (denoted as 10/10). All chemotaxis/chemokinesis experiments were performed using cells from five individual animals $(N=5)$, enumerating 10 random fields of view per chemotaxis filter per animal. Results are means \pm SEM. Above-head letters denote statistical designations: experimental groups described by distinct letters are statistically different $(P<0.05)$, while those marked by the same letters are not.

in response to specific BM-produced chemoattractive factors. To test this notion, we opened $X$. laevis femurs, flushed them to remove resident leukocytes, and incubated the resulting femur bones in medium, thereby conditioning the medium with any factors that would be produced by the BM stroma/supportive tissue. We then concentrated the conditioned medium tenfold and assessed the capacity of this conditioned medium to chemoattract LP cells and PBLs. As anticipated, both the LP cells and PBL populations displayed dose-dependent migration toward the BM-conditioned medium (Figure 3). The LP and peripheral blood cells migrating toward the BM-conditioned medium possessed somewhat mixed cytology, reminiscent of immature myeloid-lineage cells (Supplementary Figure 2).

To delineate whether this migration was gradient dependent (chemotaxis) or gradient independent (chemokinesis), we repeated the migration studies, this time adding BM stromacondition medium (tenfold concentrated) to both upper and lower chemotaxis chambers, thereby disrupting any chemoattractant gradient. This resulted in significantly diminished migration of both LP cells and PBLs (Figure 3), indicating that the factors present in the conditioned medium were eliciting chemotaxis rather than chemokinesis.

\section{$X$. laevis Peripheral Liver and Bone Marrow Stroma Possess Unique Chemokine Gene Expression Profiles}

To elucidate what chemokines might be produced by the X. laevis BM stroma, we compared the LP and BM stromal cells for their

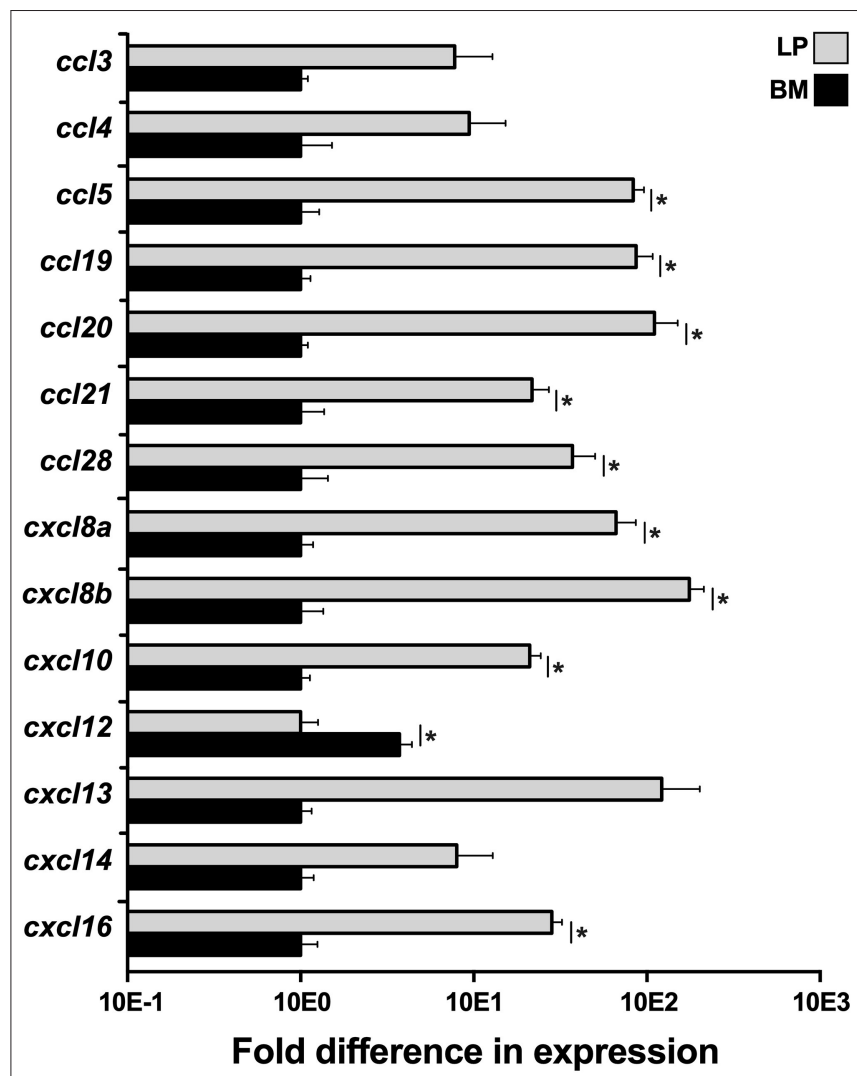

FIGURE 4 | Analysis of chemokine gene expression in $X$. laevis liver periphery and bone marrow. Frog liver periphery (LP) and bone marrow (BM) from five individual animals $(N=5)$ were examined for their expression of a panel of chemokine genes by qPCR. All gene expressions were quantified relative to the gapdh endogenous control and normalized against the lowest observed expression. Results are means \pm SEM and $\left({ }^{*}\right)$ overhead of horizontal lines denote statistical significance, $P<0.05$.

gene expression of a panel of chemokines, including $c c l 3, c c l 4$, ccl5, ccl19, ccl20, ccl21, ccl28, cxcl8a, cxcl8a, cxcl10, cxcl12, cxcl13, cxcl14, and cxcl16 (Figure 4). Most notably, the BM stromal cells possessed significantly greater transcript levels of a single chemokine, cxcl12, while the LP cells displayed greater mRNA levels of all other examined chemokines (Figure 4).

\section{CXCL12 Is Chemotactic to X. laevis LP Cells and PBLs}

To confirm the roles of the CXCL12 in the X. laevis homing of myeloid cells, we generated a recombinant form of the $X$. laevis CXCL12 (rCXCL12) and performed chemotaxis assays with LP cells and PBLs. As hypothesized, the rCXCL12 elicited concentration-dependent migration of both LP cells and PBLs (Figure 5A). Notably, at the lowest examined dose of $10^{-7} \mathrm{ng} / \mathrm{ml}$, rCXCL12 resulted in significantly greater migration of LP cells compared to PBLs, whereas significantly greater numbers of PBLs than LP cells were recruited at $10^{-1} \mathrm{ng} / \mathrm{ml}$ of the chemokine (Figure 5A). Moreover, our chemokinesis studies indicated that rCXCL12 was eliciting chemotaxis rather than chemokinesis of both LP cells and PBLs (Figure 5A). 


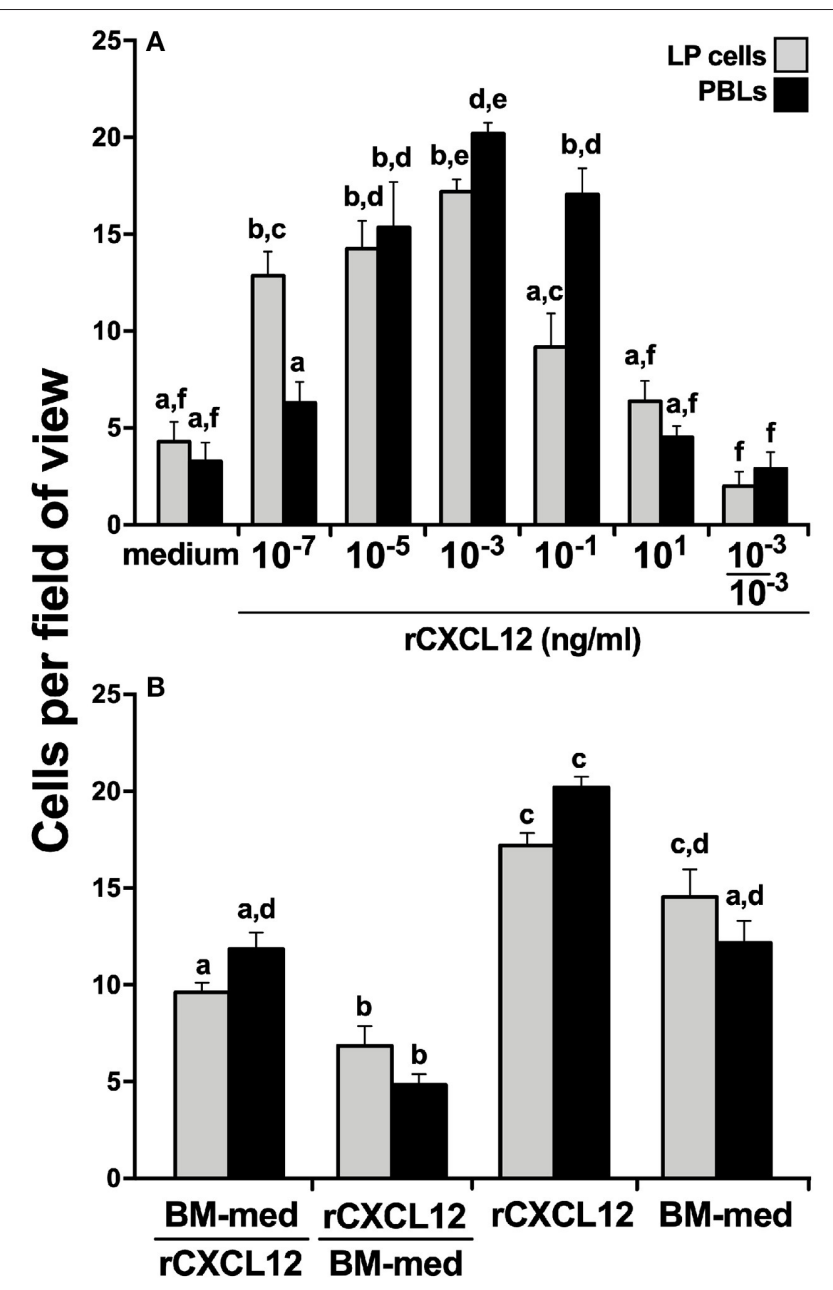

FIGURE $5 \mid X$. laevis $r C X C L 12$ is chemotactic to liver periphery and peripheral blood leucocytes. A recombinant $X$. laevis CXCL12 (rCXCL12, 10 $0^{-7}-10^{1}$ $\mathrm{ng} / \mathrm{ml}$ ) was examined for its capacity to chemoattract (A) liver periphery (LP) cells or peripheral blood leucocytes (PBLs; $10^{4}$ cells/well) with chemokinesis assessed by adding $10^{-3} \mathrm{ng} / \mathrm{ml}$ of rCXCL12 (optimal dose) to both the upper and the lower chemotaxis chambers. (B) The relative capacities of tenfold concentrated bone marrow conditioned medium (BM-med) and rCXCL12 $\left(10^{-3} \mathrm{ng} / \mathrm{ml}\right)$ to chemoattract LP cells and PBLs $\left(10^{4}\right.$ cells/well) were compared through chemokinesis experiments by adding either BM-med or rCXCL12 and rCXCL12 or BM-med to the upper and lower chemotaxis chambers, respectively (denoted as BM-med/rCXCL12; rCXCL12/BM-med) and compared to BM-med or rCXCL12 in only bottom wells. All chemotaxis/chemokinesis experiments were performed using cells from 5 individual animals $(N=5)$, enumerating 10 random fields of view per chemotaxis filter per animal. Results are means \pm SEM. Above-head letters denote statistical designations: experimental groups described by distinct letters are statistically different $(P<0.05)$, while those marked by the same letters are not.

Because the $X$. laevis BM harbor GMPs and displayed robust cxcl12 gene expression (Figure 4), while rCXCL12 was chemotactic to LP cells and PBLs (Figure 5A), we hypothesized that CXCL12 may be a major component of BM-conditioned medium. To address this notion, chemokinesis experiments were carried out using BM-conditioned medium (BM-med, obtained as described above and concentrated tenfold) and rCXCL12, with either rCXCL12 in the bottom chemotaxis chambers and with BM-med loaded into the upper wells, or vice-versa. LP cell and PBL chemotaxis was substantially reduced in either condition (Figure 5B) (significantly so when rCXCL12 was added to top wells), suggesting that indeed CXCL12 may be a major chemotactic component of BM-conditioned medium as it ablates the gradient-dependent chemotaxis elicited by BM-conditioned medium. Both LP cells and PBLs displayed a significantly greater migration toward rCXCL12 than toward the BM-med (Figure 5B), presumably owing to the greater concentration gradient established by the rCXCL12 than present in the BM-med.

\section{The rCXCL12 Chemoattracts Myeloid-Lineage Cells}

To define the lineage commitment of the rCXCL12-responsive LP cells and PBLs, we repeated the rCXCL12 chemotaxis experiment and isolated from the bottom chemotaxis chambers the LP cells and PBLs that migrated toward this chemokine. We then examined these cells for their gene expression of cxcr4, the cognate receptor for CXCL12 (43) as well as a panel of myeloid, hematopoietic, erythroid, and lymphoid cell lineage markers (Figure 6). Notably, both the LP cells and PBLs that chemotaxed toward rCXCL12 exhibited robust (compared to total input LP cells and PBLs, respectively) gene expression of CXCR4. While the LP cells chemotaxed toward rCXL12 possessed significantly lower gene expression of the macrophage csf1r (c-fms) compared to total LP cells; rCXCL12-recruited PBLs possessed significantly greater csfir mRNA levels than total PBLs, and both rCXCL12-recuited LP cells and PBLs possessed significantly greater transcript levels for the granulocyte csf3r marker than total LP and PBL cells, respectively (Figure 6). Moreover, the PBLs but not LP cells recruited toward the rCXCL12 exhibited greater expression of myeloid lineage TFs, $p u 1$, and $g f i 1$ than seen in total respective PBL and LP cells (Figure 6).

The rCXCL12-recruited LP cells and PBLs did not exhibit significantly greater levels of any of the examined HSC (tall, klf4, gata2) or erythroid (fli1, gata1, nfe2)-lineage TF genes, compared to total respective cell subsets, while the rCXCL12-recruited LP cells possessed significantly lower expression of klf4 (Figure 6). Compared to total LP cells and PBLs, the rCXCL12-recruited LP cells and PBLs exhibited significantly lower gene expression of igm [expressed by B cells; (44)], and while the recruited PBLs possessed greater $c d 4$ [expressed by $\mathrm{T}$ helper cells and some macrophages; $(45,46)]$ transcript levels, the chemotaxed LP cells exhibited greater mRNA levels of $c d 8 a$ [expressed by cytotoxic $\mathrm{T}$ cells and some dendritic cells; $(47,48)]$ (Figure 6).

\section{The X. laevis Bone Marrow Supports the Survival of Peripheral Liver-Derived Cells}

In accordance to the above findings, we reasoned that if the LP is indeed the source of myeloid cell precursors that home to the $\mathrm{BM}$, then the BM should be capable of supporting LP cell survival in vitro. To test this idea, we isolated LP cells and cultured them in vitro in semi-solid medium within flushed $X$. laevis femurs 


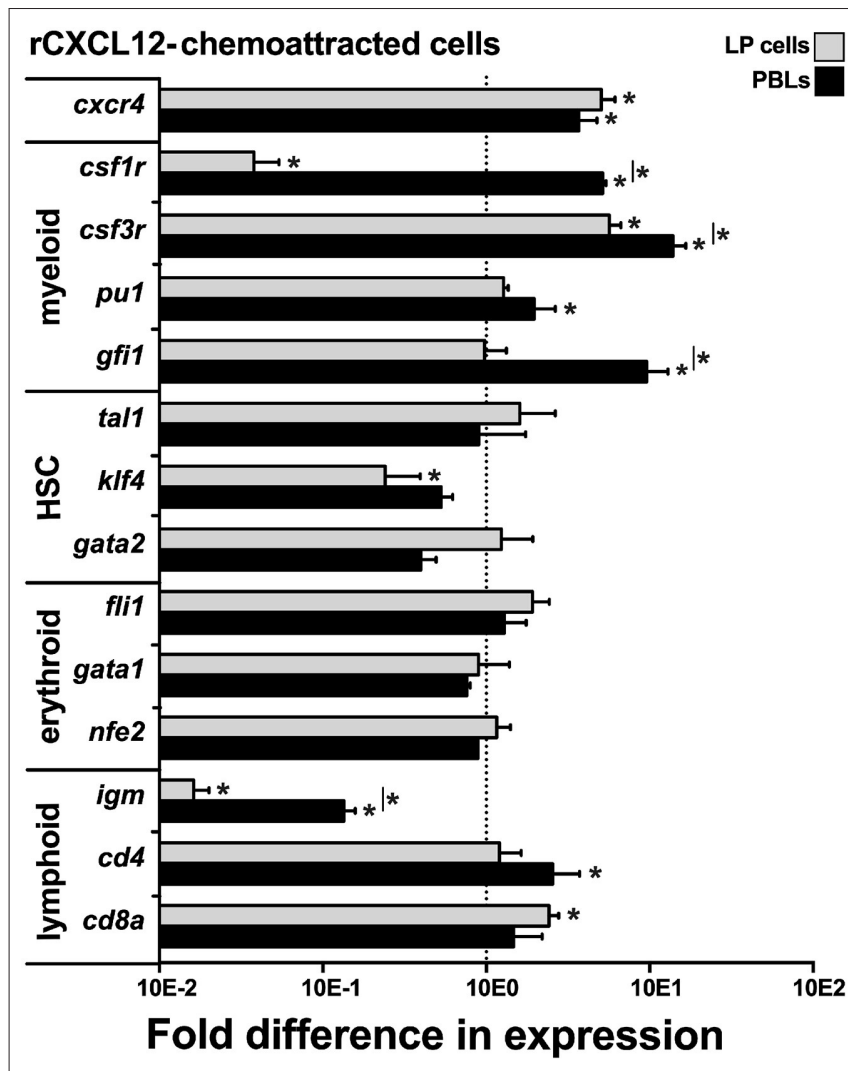

FIGURE $6 \mid X$. laevis rCXCL12 chemoattracts myeloid-lineage cells. Chemotaxis assay using the optimal concentration of rCXCL12 $\left(10^{-3} \mathrm{ng} / \mathrm{ml}\right)$ was performed on liver periphery $(\mathrm{LP})$ cells and peripheral blood leucocytes (PBLs; $10^{4} \mathrm{LP}$ cells or PBLs/well, cell from five individual frogs, $N=5$ ), and the chemoattracted cells were examined for their gene expression of crcr4 (receptor for CXCL12); lineage specific markers for myeloid: csf1r (macrophage), csf3r (granulocyte), pu1, gfi1; HSC-associated: tal1, klf4, gata2; erythroid: fli1, gata1, nfe2, and lymphoid cell populations: igm (B cell); cd4 (T helper cell); and cd8 (cytotoxic T cell) by qPCR. All gene expressions was quantified relative to the gapdh endogenous control and normalized against the corresponding gene expression observed in the LP cells or PBLS (input, indicated by the dashed line) used in these chemotaxis experiments. Results are means \pm SEM, (*) denotes statistical differences from the gene expression in total input LP or PBL population (indicated by the dashed line) and (*) above horizontal bars denote statistical differences between LP cells and PBLs, $P<0.05$.

or femurs with methanol-fixed (and washed) stroma/supportive tissue. As expected, the LP cells displayed significantly greater survival when cultured within viable femur bones as compared to femurs that had been methanol-fixed, thus indicating that the BM is capable of supporting LP cells (Figure 7).

\section{DISCUSSION}

Mammalian hematopoiesis begins in the yolk sac, shifts to the aorta-gonad-mesonephros region of the developing embryo, then to the fetal liver followed by fetal spleen, and ultimately to the bone marrow (49). Similarly, during the early life of avian species, the liver acts as a hematopoietic site, with hematopoiesis later shifting to the avian bone marrow $(5,6)$.

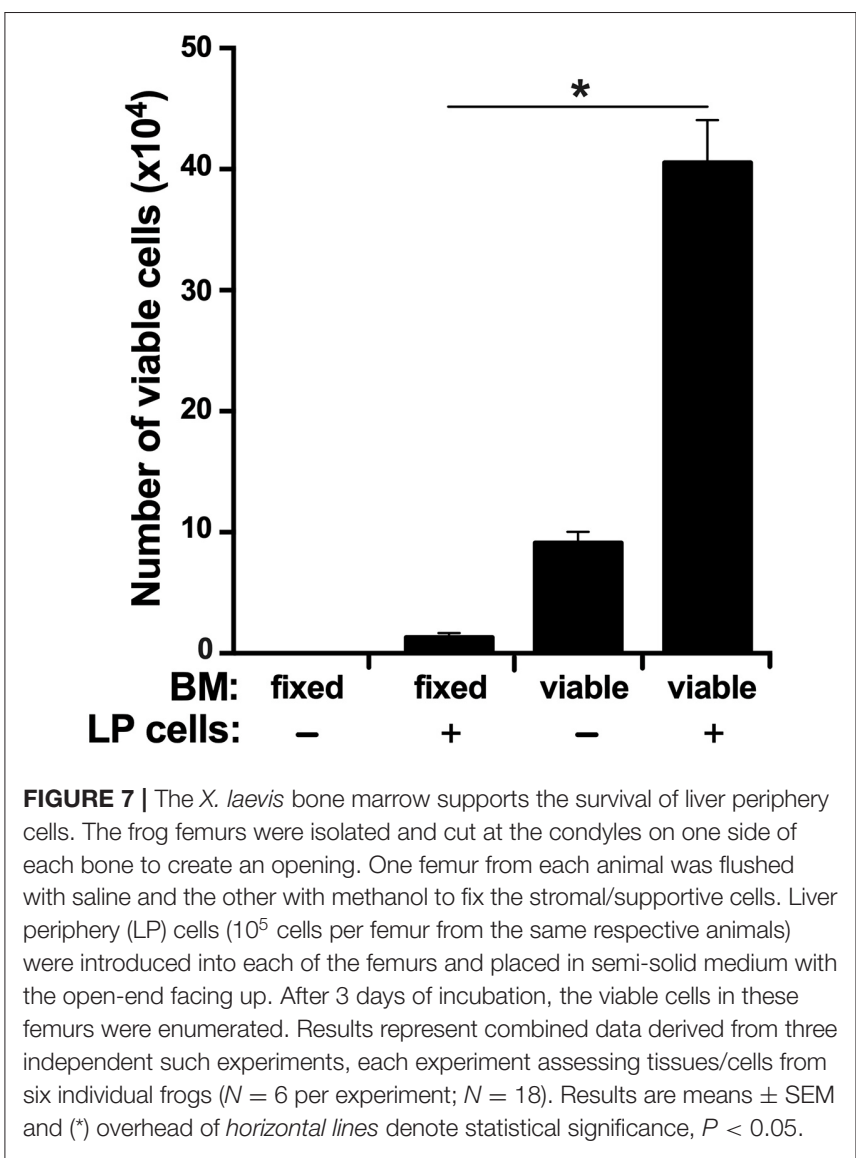

Interestingly, our previous findings indicate that hematopoiesis is segregated between different tissues in the adult $X$. laevis, with myelopoiesis occurring in the bone marrow and to our knowledge, the remaining blood cell development being facilitated by the peripheral liver (14-18). Notably, while the importance of transcription factors to hematopoiesis and lineage commitment has been well-established across vertebrates (1921 ), our present transcription factor gene and protein expression analyses of the $X$. laevis peripheral liver and bone marrow cells corroborate our previous findings $(17,18)$ that while the peripheral liver hosts most hematopoiesis of this animal, the myelopoiesis and GMPs are segregated to the X. laevis bone marrow.

Numerous factors contribute to the specialized niche microenvironments within hematopoietic sites to facilitate blood cell development. These include specific cell populations that assist in the interactions between HSCs and the supportive tissues through anchoring/mobilization and production of cytokines/growth factors and chemokines, in addition to other instructive stimuli that may facilitate hematopoietic cell maintenance and regulation $(19,50,51)$. Consistent with this, it is possible that one or several of such factors that are crucial for GMP homing, maintenance, and/or differentiation are present in the bone marrow and are absent from the peripheral liver, thus necessitating the segregation of hematopoiesis across these two sites within $X$. laevis. Interestingly, while the blood cell 
development in adult aquatic anuran amphibian species occur in their peripheral liver tissues, as illustrated in Xenopodinae (14-16), this process occurs in the bone marrow of more terrestrial anuran species $(52,53)$, presumably exemplifying a step-wise evolutionary transition of hematopoiesis from hepatic tissues to bone marrow. Supporting this theory, more recently diverged terrestrial anuran amphibians, such as those of Rana genus, utilize their bone marrow as sites for erythropoiesis (54), while in the phylogenetically older aquatic anurans such as Xenopodinae, erythropoiesis occurs in the peripheral liver and is absent from their bone marrow $(14,17)$. Perhaps this suggests that from an evolutionary standpoint, the use of bone marrow as the principal hematopoietic site co-evolved with adaptation of vertebrate life from water to land. This notion is well-corroborated by the fact that most (relatively primordial) aquatic amphibians, such as those of Gymnophiona (legless caecilians and species more closely related to them) and Urodela (newts and salamanders) orders, are devoid of bone marrow hematopoiesis $(52,55)$, whereas terrestrial salamanders of the family Plethodontidae exclusively utilize their bone marrow toward granulopoiesis and lymphopoiesis (56).

The use of bone marrow as a site of hematopoiesis by amphibians appears to have co-evolved with progressively greater vascularization of this site and coincides with adaptation toward more terrestrial (rather than aquatic) life (57). For example, the bone marrow of the Triturus pyrrhogaster newt is composed predominantly of fat cells, with very poor vascular innervation and an apparent lack of any hematopoietic activity (57). Evolutionarily primordial aquatic anurans such as Bombina and Xenopus possess relatively rudimentary vascularization of their bone marrow compared to mammals and appear to host minimal bone marrow hematopoiesis, which appears to be limited to myelopoiesis in Xenopus (57). By contrast, more recently diverged terrestrial amphibians possess bone marrow with considerably more pronounced vascularization that is more akin to that seen within the mammalian bone marrow and coinciding with much greater hematopoiesis taking place within this site (57). As bone marrow-mediated hematopoiesis appears to have co-evolved with greater vascularization of this site, it is reasonable to speculate that this vascularization in turn would facilitate more efficient migration of HSCs to and from this site in response to chemotactic cues such as CXCL12.

Chemokines are not only critical to immune responses but also perform a plethora of functions such as mediating the migration, tissue homing, proliferation, mobilization, and survival of HSCs (22). In turn, during monopoiesis csflr gene expression increases with myeloid lineage commitment $(58,59)$. Conversely, in addition to myeloid-lineage cells, csf3r (granulocyte colony-stimulating factor receptor, gcsf) is also expressed by mammalian HSCs, which facilitates CSF-3 (granulocyte colony stimulating factor, G-CSF)-mediated mobilization of HSCs out of the mammalian bone marrow into circulation $(60,61)$. Notably and compared to total LP cells, the rCXCL12-recruited LP cells possessed lower expression of $c s f 1 r$ but greater mRNA levels of csf3r. Conversely, the
rCXCL12-recruited PBLs exhibited greater transcript levels for both myeloid receptor genes as compared to total PBLs. Concurrently, the CXCL12-recruited PBLs but not LP cells possessed significantly greater gene expression of transcription factors associated with myeloid-lineage commitment. Accordingly, we postulate that in X. laevis, CXCL12 (and very likely other factors) mobilizes cell population(s) with GMP potential out of the liver periphery into blood circulation, while the commitment to the GMP lineage occurs in circulation, presumably in response to myeloid growth factors. These GMP progenitor(s) is/are then recruited to the bone marrow by the bone marrow-produced CXCL12. The significantly lower transcript levels of $c x c l 12$ in the peripheral liver compared to that of the bone marrow presumably facilitates the egress of HSCs with GMP potential, resulting in their migration toward the bone marrow through blood circulation in a CXCL12 concentration gradient-dependent manner. We anticipate that the initial GMP lineage commitment occurs en route to the bone marrow and that further lineage-specific differentiation then ensues in the $\mathrm{BM}$ in response to local cues and growth factors, giving rise to myeloid cells such as macrophages and granulocytes $(17,18)$. Indeed the mammalian CXCL12 is essential to the homing of adult HSCs to the bone marrow and is crucial to the migration of HSCs from fetal liver to the bone marrow during development $(24,25)$. It is thus intriguing that a similar phenomenon appears to facilitate the GMP population of the adult $X$. laevis bone marrow toward myelopoiesis.

HSCs of adult mammals are known to migrate predominantly toward a CXCL12 concentration gradient (62), while the activation of the HSC cell surface-expressed CXCR4 by CXCL12 is indispensable to the regulation of HSC migration during adult life (24). In fact, targeted deletion of CXCR4 results in decreased HSC pools in the mammalian bone marrow (24). Although the $X$. laevis CXCL12 has been shown to signal through CXCR4 (23), the precise role(s) of this chemokine in $X$. laevis hematopoiesis in general and myelopoiesis in particular remain to be fully defined. Notably, our present results indicate that the $X$. laevis CXCL12 is more prominently expressed by their bone marrow than their hematopoietic peripheral liver and appears to be important to the migration/homing of some sort of GMP population(s) from the liver periphery to the bone marrow. It is interesting to consider that in X. laevis, CXCL12 has evolved to mediate the migration/homing of one or few hematopoietic progenitor subsets to the bone marrow, rather than functioning (as in mammals) as a more global regulator of HSCs within their peripheral liver, which serves as their principal hematopoietic tissue (14-16). Further studies of the roles of CXCL12 across phylogenetically disparate vertebrates possessing distinct hematopoiesis strategies may elucidate what aspects of the $X$. laevis (and mammalian) bone marrow physiology dictate the use of CXCL12 toward homing of progenitor cells toward this site.

In addition to CXCL12-mediated chemotaxes, the migration of mammalian fetal hepatic HSCs to the bone marrow is influenced by a number of other factors. For example, the role of CXCL12-CXCR4 in the migration of HSCs is 
augmented by other soluble mediators including stem cell factor, whose chemotactic activity toward mouse fetal hepatic HSCs is synergistic with that of CXCL12 (63). Similarly, activation/signaling through the roundabout guidance receptor 4 (ROBO4) that is expressed by mammalian HSCs aids in the early migration of HSCs from fetal liver to fetal bone marrow and augments the CXCR4-mediated homing and population of HSCs into the adult bone marrow (64). Additionally, adhesion molecules such as cadherins, integrins, and selectins also play important roles in the movement of HSCs to distinct niches. For instance, $\mathrm{N}$-cadherin and integrin $\beta 1$ expressed on HSCs are involved in the homing and maintenance of these cells in the bone marrow $(65,66)$. Concurrently, Pselectins and E-selectins expressed by vascular endothelia in the bone marrow promote this HSC migration and homing (67). Furthermore, the migration of HSCs during development is also influenced by extracellular calcium concentration in the bone marrow, which are sensed by the HSC-expressed calciumsensing receptors (CaRs) (68). Akin to mammals, the recruitment of $X$. laevis GMP into their bone marrow and retention therein undoubtedly depends on a plethora of other factors in addition to CXCL12. Our result showing that the X. laevis bone marrow promotes the survival of liver periphery-derived hematopoietic cells supports the notion that in addition to chemokine homing, other factors likely contribute to progenitor cell-bone marrow interactions.

Phylogenetically diverged vertebrate groups possess distinct hematopoiesis strategies, presumably reflecting the physiologies and habitats of those organisms. Despite these differences, vertebrates rely on many of the same soluble mediators, such as growth factors and chemokines, to facilitate their respective blood cell development. We believe that greater understanding of the biological roles of such evolutionarily conserved mediators in the contexts of disparate animal hematopoiesis strategies will grant much clearer understanding of the evolution of vertebrate hematopoiesis.

\section{REFERENCES}

1. Hough SR, Laslett AL, Grimmond SB, Kolle G, Pera MF. A continuum of cell states spans pluripotency and lineage commitment in human embryonic stem cells. PLoS ONE. (2009) 4:e7708. doi: 10.1371/journal.pone.00 07708

2. Kondo M, Weissman IL, Akashi K. Identification of clonogenic common lymphoid progenitors in mouse bone marrow. Cell. (1997) 91:661-72. doi: 10.1016/S0092-8674(00)80453-5

3. Buza-Vidas N, Luc S, Jacobsen SEW. Delineation of the earliest lineage commitment steps of haematopoietic stem cells: new developments, controversies and major challenges. Curr Opin Hematol. (2007) 14:315-21. doi: 10.1097/MOH.0b013e3281de72bb

4. Zapata A, Leceta J, Villena A. Reptilian bone marrow. An ultrastructural study in the Spanish lizard, Lacerta hispanica. J Morphol. (1981) 168:137-49. doi: 10.1002/jmor.1051680203

5. Fellah JS, Jaffredo T, Nagy N, Dunon D. Development of the avian immune system. Avian Immunol. (2013) 23:45-63. doi: 10.1016/B978-0-12-396965-1.00003-0

\section{DATA AVAILABILITY STATEMENT}

The datasets generated for this study are available on request to the corresponding author.

\section{ETHICS STATEMENT}

The animal study was reviewed and approved by the Institutional Animal Care and Use Committee (IACUC) (approval number 15-024).

\section{AUTHOR CONTRIBUTIONS}

AY and LG designed and planned the studies. AY and PR performed the experiments. AY analyzed the data, wrote the manuscript, and prepared the figures. LG contributed to investigation, review, and editing of the manuscript.

\section{FUNDING}

This work was funded by National Science Foundation CAREER Award (IOS: 1749427) to LG.

\section{ACKNOWLEDGMENTS}

AY thanks the GWU, Department of Biological Sciences for GTA support and support from the GWU Harlan Research program. PR thanks the Thomas Jefferson High School internship program. LG thanks the GWU Department of Biology. We thank the two reviewers whose helpful comments and insightful suggestions contributed to improving this manuscript.

\section{SUPPLEMENTARY MATERIAL}

The Supplementary Material for this article can be found online at: https://www.frontiersin.org/articles/10.3389/fimmu. 2019.03015/full\#supplementary-material

6. Jaffredo T, Yvernogeau L. How the avian model has pioneered the field of hematopoietic development. Exp Hematol. (2014) 42:661-8. doi: 10.1016/j.exphem.2014.05.009

7. Dzierzak E, Speck NA. Of lineage and legacy: the development of mammalian hematopoietic stem cells. Nat Immunol. (2008) 9:129-36. doi: 10.1038/ni1560

8. Belosevic M, Hanington PC, Barreda DR. Development of goldfish macrophages in vitro. Fish Shellfish Immunol. (2006) 20:152-71. doi: 10.1016/j.fsi.2004.10.010

9. Neumann NF, Barreda DR, Belosevic M. Generation and functional analysis of distinct macrophage sub-populations from goldfish (Carassius auratus L.) kidney leukocyte cultures. Fish Shellfish Immunol. (2000) 10:1-20. doi: 10.1006/fsim.1999.0221

10. Tagoh H, Himes R, Clarke D, Leenen PJM, Riggs AD, Hume D, et al. Transcription factor complex formation and chromatin fine structure alterations at the murine $\mathrm{c}$-fms (CSF-1 receptor) locus during maturation of myeloid precursor cells. Genes Dev. (2002) 16:1721-37. doi: 10.1101/gad.222002

11. Jones CV, Ricardo SD. Macrophages and CSF-1. Organogenesis. (2013) 9:24960. doi: 10.4161 /org. 25676 
12. Pixley FJ, Stanley ER. CSF-1 regulation of the wandering macrophage: complexity in action. Trends Cell Biol. (2004) 14:628-38. doi: $10.1016 /$ j.tcb.2004.09.016

13. Fried W. Erythropoietin and erythropoiesis. Exp Hematol. (2009) 37:1007-15. doi: 10.1016/j.exphem.2009.05.010

14. Nogawa-Kosaka N, Sugai T, Nagasawa K, Tanizaki Y, Meguro M, Aizawa Y, et al. Identification of erythroid progenitors induced by erythropoietic activity in Xenopus laevis. J Exp Biol. (2011) 214:921-7. doi: 10.1242/jeb.050286

15. Hadji-Azimi I, Coosemans V, Canicatti C. B-lymphocyte populations in Xenopus laevis. Dev Comp Immunol. (1990) 14:69-84. doi: 10.1016/0145-305X(90)90009-4

16. Chen XD, Turpen JB. Intraembryonic origin of hepatic hematopoiesis in Xenopus laevis. J Immunol Baltim Md. (1995) 154:2557-67.

17. Yaparla A, Wendel ES, Grayfer L. The unique myelopoiesis strategy of the amphibian Xenopus laevis. Dev Comp Immunol. (2016) 63:136-43. doi: 10.1016/j.dci.2016.05.014

18. Grayfer L, Robert J. Colony-stimulating factor-1-responsive macrophage precursors reside in the amphibian (Xenopus laevis) bone marrow rather than the hematopoietic subcapsular liver. J Innate Immun. (2013) 5:531-42. doi: 10.1159/000346928

19. Zhu J, Emerson SG. Hematopoietic cytokines, transcription factors and lineage commitment. Oncogene. (2002) 21:3295-313. doi: 10.1038/sj.onc. 1205318

20. Kehrl JH. Hematopoietic lineage commitment: role of transcription factors. Stem Cells. (1995) 13:223-41. doi: 10.1002/stem.5530130304

21. Orkin SH. Transcription factors and hematopoietic development. J Biol Chem. (1995) 270:4955-8. doi: 10.1074/jbc.270.10.4955

22. Broxmeyer HE. Regulation of hematopoiesis by chemokine family members. Int J Hematol. (2001) 74:9-17. doi: 10.1007/BF02982544

23. Hughes CE, Nibbs RJB. A guide to chemokines and their receptors. FEBS J. (2018) 285:2944-71. doi: 10.1111/febs.14466

24. Sugiyama T, Kohara H, Noda M, Nagasawa T. Maintenance of the hematopoietic stem cell pool by CXCL12-CXCR4 chemokine signaling in bone marrow stromal cell niches. Immunity. (2006) 25:977-88. doi: 10.1016/j.immuni.2006.10.016

25. Janssens R, Struyf S, Proost P. The unique structural and functional features of CXCL12. Cell Mol Immunol. (2018) 15:299. doi: 10.1038/cmi.2017.107

26. Stebler J, Spieler D, Slanchev K, Molyneaux KA, Richter U, Cojocaru V, et al. Primordial germ cell migration in the chick and mouse embryo: the role of the chemokine SDF-1/CXCL12. Dev Biol. (2004) 272:351-61. doi: 10.1016/j.ydbio.2004.05.009

27. David NB, Sapède D, Saint-Etienne L, Thisse C, Thisse B, Dambly-Chaudière $\mathrm{C}$, et al. Molecular basis of cell migration in the fish lateral line: role of the chemokine receptor CXCR4 and of its ligand, SDF1. Proc Natl Acad Sci USA. (2002) 99:16297-302. doi: 10.1073/pnas.252339399

28. Chong SW, Nguyet LM, Jiang YJ, Korzh V. The chemokine Sdf-1 and its receptor Cxcr4 are required for formation of muscle in zebrafish. BMC Dev Biol. (2007) 22:7-54. doi: 10.1186/1471-213X-7-54

29. Braun M, Wunderlin M, Spieth K, Knöchel W, Gierschik P, Moepps B. Xenopus laevis stromal cell-derived factor 1: conservation of structure and function during vertebrate development. J Immunol. (2002) 168:2340-7. doi: 10.4049/jimmunol.168.5.2340

30. Yaparla A, Grayfer L. Isolation and culture of amphibian (Xenopus laevis) subcapsular liver and bone marrow cells. Methods Mol Biol. (2018) 1865:275-81. doi: 10.1007/978-1-4939-8784-9_20

31. Vagapova ER, Spirin PV, Lebedev TD, Prassolov VS. The role of TAL1 in hematopoiesis and leukemogenesis. Acta Nat. (2018) 10:15-23. doi: 10.32607/20758251-2018-10-1-15-23

32. Ghaleb AM, Yang VW. Krüppel-like factor 4 (KLF4): what we currently know. Gene. (2017) 611:27-37. doi: 10.1016/j.gene.2017.02.025

33. Rodrigues NP, Tipping AJ, Wang Z, Enver T. GATA-2 mediated regulation of normal hematopoietic stem/progenitor cell function, myelodysplasia and myeloid leukemia. Int J Biochem Cell Biol. (2012) 44:457-60. doi: 10.1016/j.biocel.2011.12.004

34. Zhang DE, Hetherington CJ, Chen HM, Tenen DG. The macrophage transcription factor PU.1 directs tissue-specific expression of the macrophage colony-stimulating factor receptor. Mol Cell Biol. (1994) 14:373-81. doi: 10.1128/MCB.14.1.373
35. Krishnaraju K, Hoffman B, Liebermann DA. Early growth response gene 1 stimulates development of hematopoietic progenitor cells along the macrophage lineage at the expense of the granulocyte and erythroid lineages. Blood. (2001) 97:1298-305. doi: 10.1182/blood.V97.5.1298

36. Veremeyko T, Yung AWY, Anthony DC, Strekalova T, Ponomarev ED. Early growth response gene- 2 is essential for M1 and M2 macrophage activation and plasticity by modulation of the transcription factor CEBP $\beta$. Front Immunol. (2018) 9:2515. doi: 10.3389/fimmu.2018.02515

37. de la Luz Sierra M, Sakakibara S, Gasperini P, Salvucci O, Jiang K, McCormick $\mathrm{PJ}$, et al. The transcription factor Gfil regulates G-CSF signaling and neutrophil development through the Ras activator RasGRP1. Blood. (2010) 115:3970-9. doi: 10.1182/blood-2009-10-246967

38. Tamir A, Howard J, Higgins RR, Li YJ, Berger L, Zacksenhaus E, et al. Fli-1, an Ets-related transcription factor, regulates erythropoietin-induced erythroid proliferation and differentiation: evidence for direct transcriptional repression of the Rb gene during differentiation. Mol Cell Biol. (1999) 19:4452-64. doi: 10.1128/MCB.19.6.4452

39. Andrews NC. Erythroid transcription factor NF-E2 coordinates hemoglobin synthesis. Pediatr Res. (1994) 36:419-23. doi: 10.1203/00006450-199410000-00001

40. Zheng J, Kitajima K, Sakai E, Kimura T, Minegishi N, Yamamoto M, et al. Differential effects of GATA-1 on proliferation and differentiation of erythroid lineage cells. Blood. (2006) 107:520-7. doi: 10.1182/blood-2005-04-1385

41. Hoyler T, Klose CSN, Souabni A, Turqueti-Neves A, Pfeifer D, Rawlins EL, et al. The transcription factor GATA-3 controls cell fate and maintenance of type 2 innate lymphoid cells. Immunity. (2012) 37:634-48. doi: 10.1016/j.immuni.2012.06.020

42. Medvedovic J, Ebert A, Tagoh H, Busslinger M. Pax5: a master regulator of B cell development and leukemogenesis. Adv Immunol. (2011) 111:179-206. doi: 10.1016/B978-0-12-385991-4.00005-2

43. Xu L, Li Y, Sun H, Li D, Hou T. Structural basis of the interactions between CXCR4 and CXCL12/SDF-1 revealed by theoretical approaches. Mol Biosyst. (2013) 9:2107-17. doi: 10.1039/c3mb70120d

44. Bleicher PA, Cohen N. Monoclonal anti-IgM can separate $\mathrm{T}$ cell from $\mathrm{B}$ cell proliferative responses in the frog, Xenopus laevis. J Immunol. (1981) 127:1549-55.

45. Jefferie WA, Green JR, Williams AF. Authentic T helper CD4 (W3/25) antigen on rat peritoneal macrophages. J Exp Med. (1985) 162:117-27. doi: $10.1084 /$ jem.162.1.117

46. Zhu J, Paul WE. CD4 T cells: fates, functions, and faults. Blood. (2008) 112:1557-69. doi: 10.1182/blood-2008-05-078154

47. Leahy DJ, Axel R, Hendrickson WA. Crystal structure of a soluble form of the human T cell coreceptor CD8 at 2.6 A resolution. Cell. (1992) 68:1145-62. doi: 10.1016/0092-8674(92)90085-Q

48. Shortman K, Heath WR. The CD8+ dendritic cell subset. Immunol Rev. (2010) 234:18-31. doi: 10.1111/j.0105-2896.2009.00870.x

49. Lensch MW, Daley GQ. Origins of mammalian hematopoiesis: in vivo paradigms and in vitro models. Curr Top Dev Biol. (2004) 60:127-96. doi: 10.1016/S0070-2153(04)60005-6

50. Ciau-Uitz A, Monteiro R, Kirmizitas A, Patient R. Developmental hematopoiesis: ontogeny, genetic programming and conservation. Exp Hematol. (2014) 42:669-83. doi: 10.1016/j.exphem.2014.06.001

51. Schepers K, Campbell TB, Passegué E. Normal and leukemic stem cell niches: insights and therapeutic opportunities. Cell Stem Cell. (2015) 16:254-67. doi: 10.1016/j.stem.2015.02.014

52. Grayfer L, Robert J. Amphibian macrophage development and antiviral defenses. Dev Comp Immunol. (2016) 58:60-7. doi: 10.1016/j.dci.2015.12.008

53. Padial JM, Grant T, Frost DR. Molecular systematics of terraranas (Anura: Brachycephaloidea) with an assessment of the effects of alignment and optimality criteria. Zootaxa. (2014) 3825:1-132. doi: 10.11646/zootaxa.3825.1.1

54. Carver FJ, Meints RH. Studies of the development of frog hemopoietic tissue in vitro. I. Spleen culture assay of an erythropoietic factor in anemic frog blood. J Exp Zool. (1977) 201:37-46. doi: 10.1002/jez.1402010105

55. Bleyzac P, Cordier G, Exbrayat J-M. Morphological description of embryonic development of immune organs in Typhlonectes compressicauda (Amphibia, Gymnophiona). J Herpetol. (2005) 39:57-65. doi: 10.1670/0022-1511(2005)039[0057:MDOEDO]2.0.CO;2 
56. Curtis SK, Cowden RR, Nagel JW. Ultrastructure of the bone marrow of the salamander Plethodon glutinosus (Caudata: Plethodontidae). J Morphol. (1979) 160:241-74. doi: 10.1002/jmor.1051600302

57. Tanaka Y. Architecture of the marrow vasculature in three amphibian species and its significance in hematopoietic development. Am J Anat. (1976) 145:485-97. doi: 10.1002/aja.1001450407

58. Stanley ER. Lineage commitment: cytokines instruct, at last! Cell Stem Cell. (2009) 5:234-6. doi: 10.1016/j.stem.2009.08.015

59. Mossadegh-Keller N, Sarrazin S, Kandalla PK, Espinosa L, Stanley ER, Nutt SL, et al. M-CSF instructs myeloid lineage fate in single haematopoietic stem cells. Nature. (2013) 497:239-43. doi: 10.1038/nature12026

60. Greenbaum AM, Link DC. Mechanisms of G-CSF-mediated hematopoietic stem and progenitor mobilization. Leukemia. (2011) 25:211-7. doi: $10.1038 /$ leu.2010.248

61. Bernitz JM, Daniel MG, Fstkchyan YS, Moore K. Granulocyte colony-stimulating factor mobilizes dormant hematopoietic stem cells without proliferation in mice. Blood. (2017) 129:1901-12. doi: 10.1182/blood-2016-11-752923

62. Wright DE, Bowman EP, Wagers AJ, Butcher EC, Weissman IL. Hematopoietic stem cells are uniquely selective in their migratory response to chemokines. J Exp Med. (2002) 195:1145-54. doi: 10.1084/jem.20011284

63. Christensen JL, Wright DE, Wagers AJ, Weissman IL. Circulation and chemotaxis of fetal hematopoietic stem cells. PLoS Biol. (2004) 2:E75. doi: 10.1371/journal.pbio.0020075

64. Smith-Berdan S, Nguyen A, Hassanein D, Zimmer M, Ugarte F, Ciriza J, et al. Robo4 cooperates with Cxcr4 to specify hematopoietic stem cell localization to bone marrow niches. Cell Stem Cell. (2011) 8:72-83. doi: $10.1016 /$ j.stem.2010.11.030
65. Ciriza J, Hall D, Lu A, Sena JRD, Al-Kuhlani M, García-Ojeda ME. Single-cell analysis of murine long-term hematopoietic stem cells reveals distinct patterns of gene expression during fetal migration. PLoS ONE. (2012) 7:e30542. doi: 10.1371/journal.pone.0030542

66. Potocnik AJ, Brakebusch C, Fässler R. Fetal and adult hematopoietic stem cells require betal integrin function for colonizing fetal liver, spleen, and bone marrow. Immunity. (2000) 12:653-63. doi: 10.1016/S1074-7613(00) 80216-2

67. Ciriza J, García-Ojeda ME. Expression of migration-related genes is progressively upregulated in murine lineage-Sca-1+c-Kit + population from the fetal to adult stages of development. Stem Cell Res Ther. (2010) 1:14. doi: $10.1186 /$ scrt14

68. Lam BS, Cunningham C, Adams GB. Pharmacologic modulation of the calcium-sensing receptor enhances hematopoietic stem cell lodgment in the adult bone marrow. Blood. (2011) 117:1167-75. doi: 10.1182/blood-2010-05286294

Conflict of Interest: The authors declare that the research was conducted in the absence of any commercial or financial relationships that could be construed as a potential conflict of interest.

Copyright (c) 2020 Yaparla, Reeves and Grayfer. This is an open-access article distributed under the terms of the Creative Commons Attribution License (CC BY). The use, distribution or reproduction in other forums is permitted, provided the original author(s) and the copyright owner(s) are credited and that the original publication in this journal is cited, in accordance with accepted academic practice. No use, distribution or reproduction is permitted which does not comply with these terms. 